\title{
Globalization Comparative Countries \\ and Income Inequality: Analysis of the European
}

\author{
Irina Atanasova ${ }^{1, *}$, Tsvetomir Tsvetkov ${ }^{1}$ \\ ${ }^{1}$ South-West University "Neofit Rilski", Department of Economics, Blagoevgrad 2700, Bulgaria
}

\begin{abstract}
.
Research background: The globalization of the European countries within the EU and the Eurozone is primarily economic and is expressed by the free trade and the movement of capital and labour, which determines the incomes and the GDP. Globalization and its impact on inequality is becoming an essential and problematic issue, especially in the context of on-going economic integration processes between the countries in Europe, which seek to converge their economic, social and political systems in the Euro area. The process of inequality has become even more relevant in the context of globalization.

Purpose of the article: The paper aims to examine the impact of globalization on the inequality in the developed and the emerging economies in Europe.

Methods: On the basis of an econometric assessment, a comparative analysis of the effect of globalization on the inequality in the developed European countries and the emerging countries is carried out.

Findings \& Value added: The paper analyses the essential aspects and the effects of the income inequality dynamics, both horizontally and vertically. It also addresses the question of whether the effect of globalization on the economic growth and the inequality is the same for the developing and the developed countries, respectively. Based on the research, seven important conclusions are reached.
\end{abstract}

Keywords: globalization; inequality; economic growth

JEL Classification: F63; D31

*Corresponding author: irina atanasova@yahoo.com 


\section{Introduction}

The globalization of the European countries within the EU and the Eurozone is primarily economic and is expressed by the free trade and the movement of capital and labour, which determines the incomes and the GDP. Financial globalization can lead to a variety of outcomes: (i) domestic capital flight and ambiguous effects on net capital flows, investment, and growth; (ii) capital inflows and higher investment and growth; or (iii) volatile capital flows and unstable domestic financial markets [1].

Uncovering the effect of globalization on economic growth is worthy in the era of globalization as the net impact of globalization on economic growth still remains puzzling [2]. Kilic [3] considers that even though the globalization generates opportunities for some countries' economies and positively promoting their economic growth, it also triggers off poverty, inequality, and negative economic growth for others

According to Paul Krugman and Anthony J. Venables [4] globalization affects the real income as a consequence of the emerging costs and their dynamics. Therefore, in the process of globalization there is a tendency for unevenly distributed effects on the inequality and the economic growth in the various regions involved in the process of globalization due to the declining dynamics of emerging transport costs. Inequality will increase in one region and decrease in other and there will be a differentiation between inequalities in the two regions as well.

Zhou [5] empirically tests the relationship between globalization and inequality in 60 countries, which are divided into groups. The groups cover highly developed countries, developing countries and countries that are in the restructuring of their economic systems. Globalization has been found to reduce inequality and the authors describe this relationship as sustainable over time.

Pan-Long Tsai [6] criticizes the approach for the selection of the countries that are included in the panel data of the study by Lei Zhou, Basudeb Biswas, Tyler Bowles and Peter J. Saunders, as well as their thesis that globalization has a beneficial effect on inequality. They argue that globalization increases the inequality in the underdeveloped countries.

Avik Chakrabarti [7], argues that international trade influences income inequality. $\mathrm{He}$ makes two main conclusions. The first conclusion is that the more integrated is the country's economy in international trade, the more domestic inequality is reduced. The second conclusion is that economic growth leads to an increase in international trade, which in turn leads to a reduction in inequality and an increase in economic growth.

According to Joseph Stiglitz [8] globalization is a process that leads to the increase of the inequality. However, his thesis is that the consequences of globalization depend on the way and the purpose of the governance. Joseph Stiglitz [9] argues that inequality is increasing in most countries and that only a small proportion of all countries in the world have a declining trend of inequality.

Considering the effect of globalization on the inequality viewed through the impact of international trade in Richard B. Freeman's research [10] and John David Richardson's research [8], the general conclusion is that international trade leads to an increase in the inequality.

Andreas Bergh and Therese Nilsson [11] explore the relationship between globalization and inequality, as well as the relationship between economic freedom and inequality. They conclude that free trade is linked to inequality, and that social and economic globalization increase inequality. The authors present results that illustrate that economic freedom leads to increased inequality in the developed countries, and the social globalization induces inequality in less developed countries. 
In the present study, two groups of countries are considered, which are conditionally divided into developing economies and developed economies. The group of emerging economies include Bulgaria, Romania, Estonia, Lithuania, Latvia, Slovenia, Slovakia, the Czech Republic, Poland and Hungary. And the group of developed countries include Germany, France, Italy, Spain, Denmark, the Netherlands, Belgium, Luxembourg, Austria and Sweden. The purpose of the article is to examine the impact of globalization on inequality and the GDP. The goal is achieved through the application of panel regression analysis.

\section{Method}

The variables that construct the regression model are: GDP-real, GDP per capita, Gini coefficient and KOFGI-Globalization Index, overall. The Eurostat statistics database and the statistics of KOF Swiss Economic Institute [12] is used. The Globalization Index - KOF was first introduced by Axel Dreher [13]. The Globalization Index covers three sub-indices. These include the index of economic globalization, the index of political globalization and the index of social globalization. These three indices make up the original aggregate index of globalization. This document uses the revised globalization index, which is modelled and constructed by Savina Gygli, Florian Haelg, Niklas Potrafke and Jan-Egbert Sturm [14]. The revised index includes not only economic, social and political globalization, but financial and trade globalization as well, and examines the globalization in the context of de facto and de jure development over time, as the variables are being time-weighted [15].

The primary sample aggregate will be examined for a random component and the immobility of the traits over time with the following tests: Levin, Lin \& Chut, ADF - Fisher Chi-square, PP - Fisher Chi-square. The generalized process of random immobility of the statistical sample can be expressed by the following mathematical equations:

$$
\mathrm{E}\left(\mathrm{y}_{t}\right)=\mu
$$

$$
\begin{gathered}
\mathrm{E}\left(Y_{t}-\mu\right)\left(Y_{t}-\mu\right)=\sigma^{2}<\infty \\
\mathrm{E}\left(Y_{t-1}-\mu\right)\left(Y_{t-2}-\mu\right)=Y_{t_{2}-t_{1}} \forall t_{1}, t_{2} \\
\mathrm{~V} y_{t}=\alpha y_{t-1}+\beta x_{t}+\varepsilon_{t}
\end{gathered}
$$

where: $\mathrm{y}$ - dependent variable; $\alpha$ - regression coefficient; $\beta$ - regression coefficient; $\mathrm{x}-$ independent variable; $\epsilon$ - variable of interference.

Equations (1), (2), (3), express the random component in the statistical sample, and equation (4) expresses the independent deviations in the statistical features and that the variance is constant. The condition of independent and constant dispersion of statistical characteristics requires inequality $\mathrm{H}_{1}: \alpha \leq 0$.

The regression model applied in this paper can be expressed by the following mathematical equation:

$$
\mid \begin{aligned}
& \gamma=\alpha+\beta \chi_{t}+\mu \\
& \delta=\alpha+\beta \chi_{t}+\mu \\
& \delta=\alpha+\beta \gamma_{t}+\mu
\end{aligned}
$$

where: $\gamma$-Aggregate per capita income (GDP); $\chi$ - Globalization (KOFGI) $; \delta$ - Income inequality (Gini); $\mu$-term of the equation. 
The system of equations above illustrates the relationship between globalization and income inequality, as well as the relationship between globalization and aggregate income per capita and the relationship between aggregate income per capita and the income inequality. The connections between the different variables and the interaction between them is evident, which is decisive for each of the described connections.

\section{Results}

First, the empirical results of the group of countries that are characterized as emerging economies are considered. The first result to be considered are the tests that examine the random component and the immobility of the traits over time. After the study of the characteristics of the statistical population, it is established that the ongoing process is characterized by a disturbed random component and tendencies that are transmitted between the features in the statistical population. . The variance is not constant.
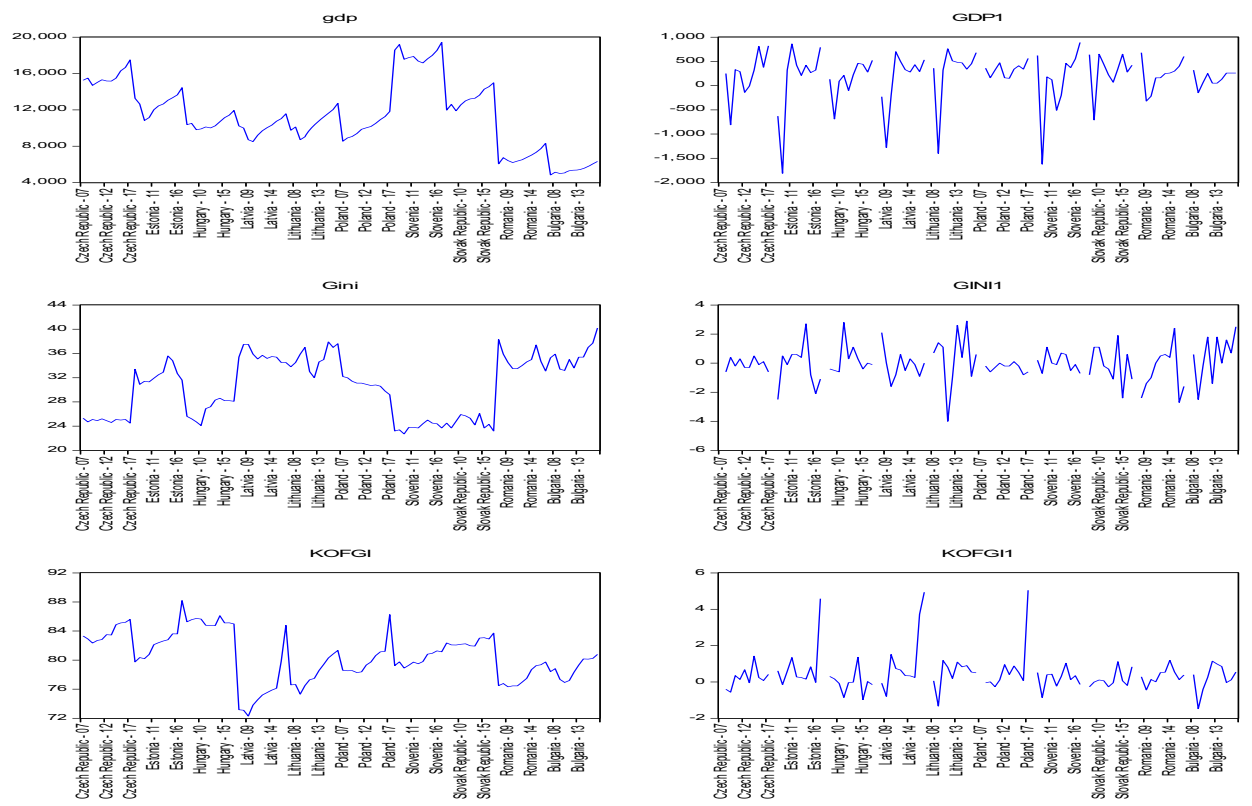

Fig. 1. Generalized panel test for stationarity. Source: Author's calculations

It is clear that inequality has been distorted $\mathrm{H}_{1}: \alpha \leq 0$ and acquired the form $\mathrm{H}_{0}: \alpha=0$. This makes it necessary to do the following transformation

$$
\mathrm{V} \gamma=\gamma_{j t}-\gamma_{j t-1} \Rightarrow \mathrm{V} \gamma=f\left(\mathrm{~V} \chi_{i t}^{\prime} \mathrm{V} \mu_{i t}\right)
$$

The mathematical transformation

$$
H_{0 t-1}: \alpha_{t-1}=0 \Rightarrow H_{1 t}: \alpha_{t} \leq 0
$$

illustrates that in the statistical population there is a stable random component and a constant variance.

The impact of globalization on the income inequality of the group of countries that are characterized as developing economies is insignificant. The index of the impact of globalization on income inequality is $(-0.038410)$, but with a $75 \%$ probability it can be stated that the impact of globalization does not interact with income inequality in developing European economies. 

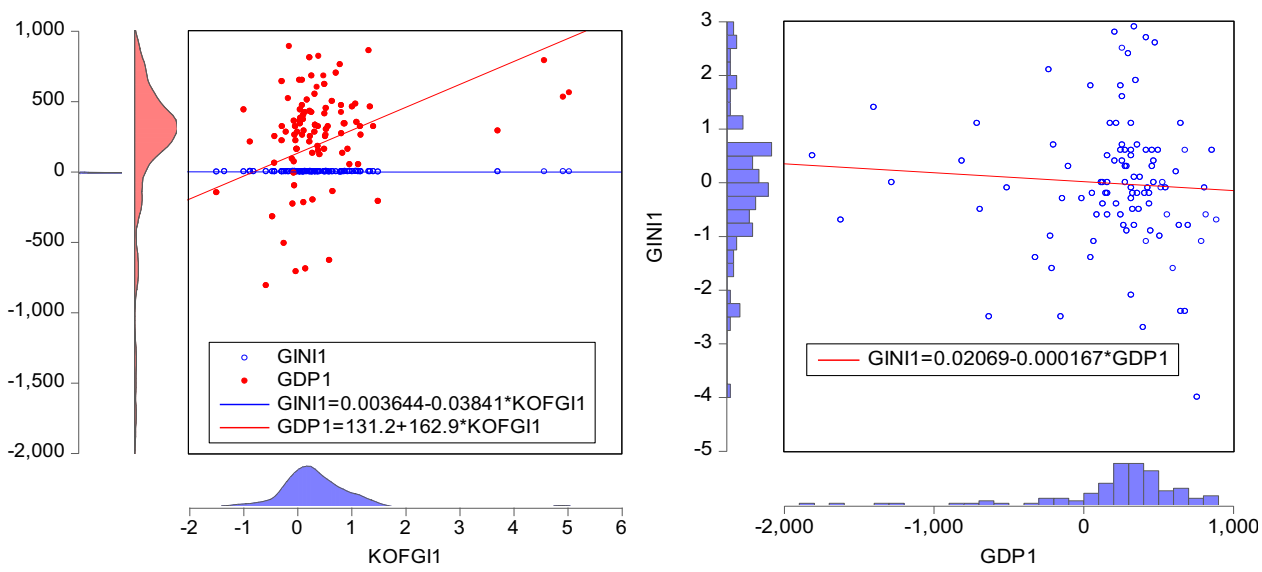

Fig. 2. The impact of globalization on income inequality and GDP and The impact of GDP on income inequality in emerging economies.

Source: Author's calculations

Therefore, an empirical argument can be deducted, as it can be seen from Figure 2, that globalization (KOFGI) is neutral, regarding income inequality. This neutrality for the considered period is due to the reverse process in the European integration process, which has been observed since the outbreak of the Great Recession of 2008. The process of globalization includes undergoing de-globalization tendencies, which are becoming more and more prominent. At the same time, the impact of globalization on the economic growth of the countries, which are in the group of developing economies is very strong and directly and positively affects the growth of the GDP of the developing countries.

GDP growth, which is induced by the economic integration, does not affect income inequality. This clearly indicates that globalization has no indirect effect on income inequality, and that the redistribution of aggregate income in emerging economies is neutral to income inequality.

Before considering the impact of globalization on the developed countries in Europe, the random component and the variance in the panel of the group of developing countries must be analysed. 


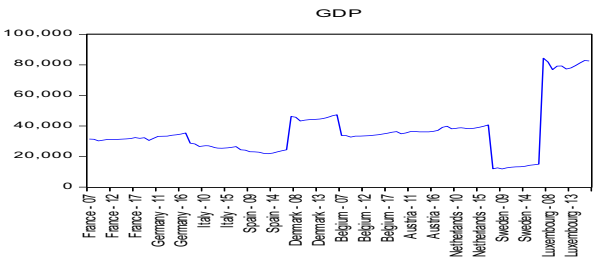

GINI

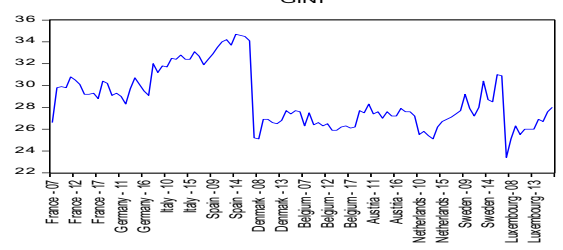

KOFGI

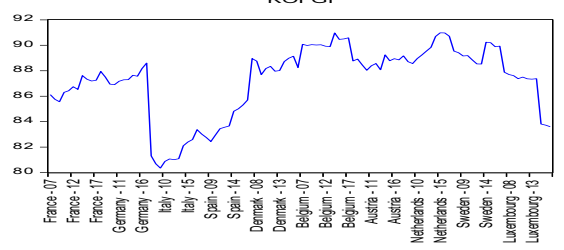

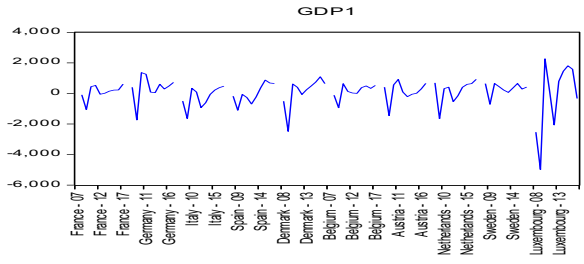

GINI1

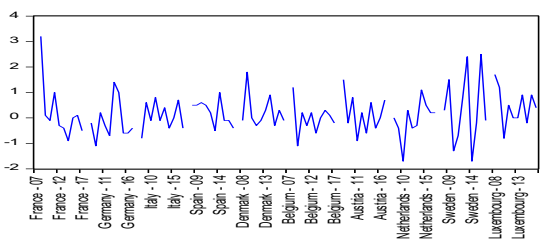

KOFGI1

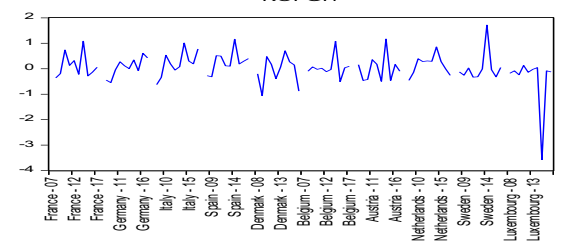

Fig. 3. Generalized panel test for stationarity. Source: Author's calculations

The random component is disturbed and the dispersion is again not constant. After the mathematical transformation, which is described above in the developing economies, the statistical population acquires a random component and a constant variance.
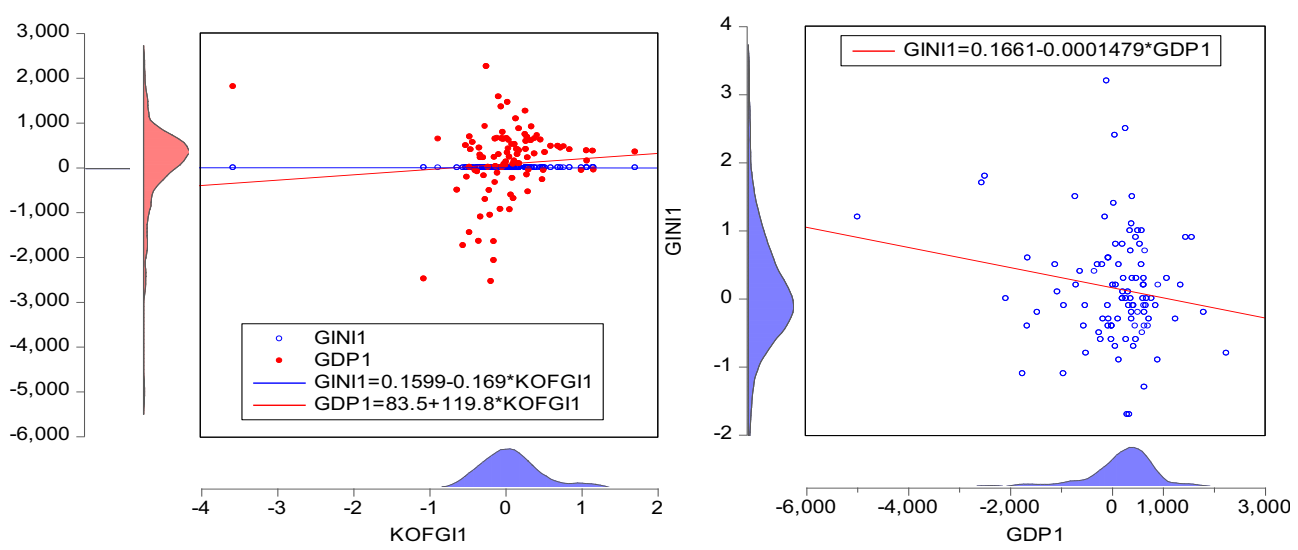

Fig. 4. The impact of globalization on income inequality and GDP and The impact of GDP on income inequality in developed economies

Source: Author's calculations

Globalization in developed countries does not affect income inequality, nor does it affects GDP. However GDP has a favourable effect on inequality, as inequality decreases with the increase of the GDP, but with a very small coefficient (-0.000148). Although GDP has a positive effect on inequality, it is not a transmission channel for globalization. 


\section{Discussion}

The impact of globalization on income inequality in developing and developed countries registers neutrality, i.e. globalization does not affect income inequality in both groups of countries. Globalization has a strong impact on the GDP of developing countries, with a direct and positive impact. While, considering the developed countries, globalization does not affect the dynamics of GDP.

Gross domestic product in developing countries does not affect income inequality. While in developed countries GDP leads to a slight reduction in income inequality, although it is insignificant, there is a weak positive correlation between economic growth and income growth. Taking into account the impact of GDP on income inequality in developed countries, which is favourable to GDP, is an argument for an effective tax policy.

From a theoretical point of view, a process of uneven effect of globalization on GDP, as well as of GDP on the inequality of the two groups of countries is established. It can be said that the present conclusions are close to the thesis of Paul Krugman and Anthony J. Venables. The conclusion, based on the empirical argument that globalization does not affect income inequality in both groups of countries does not invalidate the thesis of unequal action on different groups of countries, it only confirms that the process of globalization is in a phase of restructuring and global trends, which neutralize the direct and indirect impact of globalization on income inequality, but do not completely eliminate this impact, but simply make it latent.

\section{Conclusion}

The process of the impact of globalization on income inequality and the GDP in the developing and the developed countries has been researched, as well as the impact of the GDP dynamics on inequality. The following conclusions are reached. The first conclusion is that globalization does not affect income inequality. The second conclusion is that globalization has a positive effect on the GDP of the developing countries. The third conclusion is that globalization does not affect the GDP of the developed countries. The GDP of the developing countries does not affect income inequality. The GDP of the developed countries has a very small but positive effect on income inequality. The sixth conclusion establishes the uneven impact of globalization on the GDP of the developing and the developed countries. And the last conclusion, it that there is anti-globalization restructuring processes, which maintain the link between globalization and income inequity in a latent state.

These conclusions and the research require further development and even more in-depth analyses. Therefore this document does not claim to be indisputable and that it does not need additional and more precise research tools and analyses.

\section{References:}

1. Broner, F., Ventura, J. (2016). Rethinking the Effects of Financial Globalization. The Quarterly Journal of Economics, 131(3), 1497-1542.

2. Hasan, M. A. (2019). Does globalization accelerate economic growth? South Asian experience using panel data. Economic Structures, 8, 26. 
3. Kilic, C. (2015). Effects of globalization on economic growth: panel data analysis for developing countries. Econ Insights Trends Chall, 4(127), 1-11.

4. Krugman, P., Venables, A. J., (1995). Globalization and the Inequality of Nations. The Quarterly Journal of Economics, 110(4), 857-880.

5. Zhou, L., Biswas, B., Bowles, T., Saunders, P. J. (2011). Impact of globalization on Income Distribution Inequality in 60 countries. Global Economy Journal, 11(1), 1-18.

6. Tsai, P. L., Huang, C. H., Yang, C. Y. (2012). Impact of Globalization on Income Distribution Inequality in 60 Countries: Comments. Global Economy Journal, 12(3), 110 .

7. Chakrabarti, A. (2000). Does Trade Cause Inequality. Journal of Economic, 25(2), 121.

8. Stiglitz, J. (2002). Globalization and its Discontents. New York: WW Norton.

9. Stiglitz, J., (2006). Making Globalization Work. New York: WW Norton.

10. Freeman, R. B., (1995). Are Your Wages Set in Beijing? Journal of Economic Perspectives, 9(3), 15-32.

11. Richardson, J. D. (1995). Income Inequality and Trade: How to Think, What to. The Journal of Economic Perspectives, 9(3), 33-55.

12. Bergh, A., Nilsson, T. (2010). Do liberalization and globalization increase income inequality? European Journal of Political Economy, 26(4), 488-505.

13. KOF Swiss Economic Institute (2020). KOF Globalisation Index. Retrieved from : https://kof.ethz.ch/en/forecasts-and-indicators/indicators/kof-globalisation-index.html

14. Dreher, A. (2006). Does globalization affect growth? Evidence from a new index of globalization. Applied Economics, 38(10), 1091- 1110.

15. Gygli, S., Haelg, F., Potrafke, N., Sturm, J. E. (2019). The KOF Globalization Index revisited. The Review of International Organizations, 14(3), 543- 574. 